\title{
Market Change: How to Transform and Upgrade Luxury Goods in the New Era -Taking the LV Brand for Example
}

\author{
Jingyu $\mathrm{Gu}^{1, *, \dagger}$, Yi Liang ${ }^{2, \dagger}$, Ruoshui Wang ${ }^{3, \dagger}$, Pinghao Zhang ${ }^{4, \dagger}$ \\ ${ }^{1}$ KingLee High Schoole, Zhengzhou, Henan, China 450000 \\ ${ }^{2}$ America University, Washington, DC 20016 \\ ${ }^{3}$ University of San Diego, School of Business, San Diego, CA, United States 92110 \\ ${ }^{4}$ Shenyang Jianzhu University, School of Municipal and Environmental Engineering, Shenyang, Liaoning, China \\ 110000 \\ *Corresponding author: Email: ruoshuiwang@sandiego.edu \\ These authors contributed equally.
}

\begin{abstract}
As millennials who are highly educated, possess adequate economic resources, and have a completely different consumption outlook from previous generations start to occupy the main luxury market, luxury brands must make certain changes to cater to the new generation of consumers so as not to be abandoned by the times and regain the market. The subject of this paper is how to transform and upgrade luxury brands to seize the market in this emerging era. This paper intends to take the brand Louis Vuitton (LV) as the primary case study object and combine case study methods with secondary data analysis to explore related issues of luxury goods transformation. Through investigation, it has been found that the LV brand presents its characteristics in terms of marketing strategy concept, product design, and selection of co-name and spokesperson with other brands. On this basis, by examining the three characteristics mentioned above, this paper summarizes the main trends of luxury brand transformation and its reasons. In research and investigation, the literature and data in relevant fields are not abundant at present, so this paper is innovative in the topic selection. Moreover, the luxury market is still in the transition stage, so this research has some frontiers and practical significance for future related research.
\end{abstract}

Keywords: Luxury brand transformation, marketing strategy, LV brand, younger consumers

\section{INTRODUCTION}

With the development of the era and cultural progress, millennials have replaced the previous generation of consumers and dominated the market with a new and completely differentconcept, becoming a new generation of consumers. However, due to the huge differences between different generations of consumers, luxury brands have had to upgrade and transform to meet the demands of the new market to occupy the market. According to China Luxury Market Research 2017, in mainland China began to rebound strongly in the third quarter of 2016 after experiencing a three-year slowdown. It reached $20 \%$ growth in 2017, with millennials becoming the main driving force to define new luxury trends and accelerate luxury consumption growth in 2017.[1] With the increasingly powerful group of millennials, making luxury products "younger" has become an inevitable challenge for luxury brands and the keyword for the whole industry. Hermes entered the beauty industry, Celine launched its first standalone menswear collection, Fendi built luxury residences. All of this reflects the ambition of luxury brands to change traditional perceptions. Keeping pace with the times and following the trends are the essence of luxury survival.

LV has abandoned its traditional style and brand history, and has chosen a brand-new marketing strategy through which to enter the young market. The collaboration between LV and Riot to customize unique hard phone cases for the 2019 Global League of Legends Finals Summon Trophy and the corresponding co-branded skin has been called a milestone inflection point in the fashion industry. As a competitive game launched by the United States Riot Company, League of 
Legends has developed to today with hundreds of millions of loyal players and has become the ceiling of competitive games. According to Electronic Sports Marketing Brands 2019 report, more than 50 percent of its players are between 18 and 34 years old [2]. The number of people who spend hundreds of RMB on game skins is far greater than the number of consumers of LV brands. Therefore, this marketing of LV can be said to have not only successfully entered into this group of young consumers, but also completed a brand penetration in a way close to the spirit of the young group and the identity of their values.

Moreover, what is most interesting to us is that Louis Vuitton is well known in the handbag and suitcase world but has little presence in menswear and fashion. According to Curiosity Daily, Louis Vuitton has 450 stores worldwide, of which only 150 have clothing. What made LVMH decide to replace its menswear director under such circumstances? In 2017 sales rose by $13 \%$ to $€ 42.6$ billion, with Louis Vuitton contributing greatly. Nicolas Ghesquière, the creative director at Louis Vuitton at the time, was safe in his place. Therefore, some people said that the creative director Virgil Abloh today was still young and without any substantial achievements, so there was not much room for development. What interests us is that under such circumstances, LV did not choose to continue on the path of stable brand development but boldly made changes. For example, LV made waves in the market with their appointment of Abloh; Louis Vuitton gradually accelerated its expansion of the market and created new concepts, starting collaborations with artists and international brands such as Supreme, KAWS, and Takashi Murakami to create trends and pieces that became popular worldwide.

More, as mentioned above, LV made great efforts to enter the modern world of young people and reached cooperation with Riot gaming Company which is running the game League of Legend.

The game skins and trophy trunks they create are industry landmarks, leaving behind products that can be sold on the auction block. With this in mind, what role do these business methods and marketing measures play in the sustainable development or transformation of LV?

Given the above problems, we have decided that our research object is the marketing strategy of Louis Vuitton, and we have adopted the methods of case study and secondary data collection to explore the marketing strategy of Louis Vuitton in the context of the consumer subject and the changing of the times. In our study, we compared the past and present marketing strategies of Louis Vuitton. More specifically, we are comparing the strategies when the majority of luxury consumers were born in the 1970s and 1980s with the marketing strategies of Louis Vuitton when the majority of consumers are so-called millennials who were born decades later, up to the year 2000.

\section{LITERATURE REVIEW}

\subsection{The transformation of luxury brands}

According to our survey, although the current research on luxury transformation is not very rich, we can realize that luxury transformation has an interdisciplinary perspective from the little literature available. Advertising communication, marketing, and design are all concerned with this problem. Research on the transformation of luxury goods can be roughly divided into three categories. The first category focuses on the reasons for the transformation of luxury brands. Tan Shuang, a scholar, believes that highly educated and economically independent millennials have become the main consumers. Their consumption concepts are totally different from those of the previous generation, which forces luxury brands to transform to occupy the market. [3] The most vital aspect of the second category is the evaluation of luxury brand transformation. The scholar Huang Xinya takes IMC integrated communication theory as the foothold and Gucci brand as the starting point. In the meantime, she initiated in-depth academic thinking on current problems. She provided suggestions in the transformation and development of fashionable traditional luxury brands and the developmental conventional luxury direction brand transformation in the future [4]. The third category mainly concentrates on the specific methods of the change of luxury brands. The scholar Yi Xin analyzes the successful transformation of Gucci. This includes how brand transformation strategy was proposed and implemented; why millennials are such loyal customers, and the reference significance for other traditional luxury brands. Throughout the current research on luxury goods, we can conclude that more scholars pay attention to the reasons and specific methods for the transformation of luxury brands [5].

\subsection{Summary of research contents}

According to several studies, the main consumer groups have already become largely young.

According to a Boston Consulting Group (BCG), millennials have become the mainstream group of luxury consumers in China, with an average age of 28, which is about ten years younger than the global average [6]. Among them, consumers aged between 18 and 20 accounts for $26 \%$; that is to say, nearly $1 / 3$ of Chinese luxury consumers are very young, which means that they begin to enter the first stage of luxury consumption as they graduate from school and enter the workforce. At present, the classic design of LV has gradually started to cater to young people. They have begun to abandon the traditional design style of older times and have designed more products that combine modern trends. LV has also 
been advertising and cooperating on online platforms such as TikTok and Weibo, which young people dominate.

Our main research content is how marketing strategy has changed as the trend of brand consumers becoming younger on average has become more pronounced.

\subsection{Centennial brand expands product types}

LV is a brand with a long history. Over the past 150 years, whether it was predominating the royal court or the general public, every piece of LV quality is a fashion epitome of that era. Innate nobility and influence are the essences of this brand. However, where the Internet and millennials have more independent consumption views, LV has not stuck to the convention nor adhered to the delicate but outdated development style. Instead, LV has made bolder and bolder efforts to cooperate with contemporary fashion brands, and has launched popular worldwide series, so that their unique logo has become integrated into more and more top fashion products. The Louis Vuitton/Supreme collaboration, for example, has sold a denim jacket for nearly $\$ 20,000$. People put off by the high prices, and even now, several years later, these co-branded products are still on the market. In Luxury Market 2020: Unstoppable authors say that millennials are the main force of online luxury consumption, with their first purchase of luxury goods made at the age of 20 on average. [7]

More noteworthy is that millennials are more likely than other generations to prefer niche and co-branded products [8]. LV captures the modern young love of curiosity and willingness to spend money. Working with up-and-coming brands that might appear to be lowering their status have instead successfully brought them closer to millennial consumers. For example, Louis Vuitton cooperated with Riot Company to launch the first game hero wearing an entire LV outfit in League of Legends history and created the most expensive hero skin on the platform. In addition, leather boxes once thought to be reserved for castles and museums no longer contain antiques and clothes but trophies for the most popular gaming events of the day.

\subsection{Follow the trend of The Times}

According to the development and change of the times, the technological world has also brought unlimited development possibilities to society. The lives of most children are inextricably linked to electronic products. LV can stand out among many luxury brands because it keeps up with the pace of the times and has not been abandoned by this technological era. It can be understood from the scholar article: When LV realized that electronic products had already occupied most of the market, it cooperated with League of Legends and launched a new skin. [9] In the past, brand spokespersons were all internationally renowned stars, such as Angelina Jolie, Scarlett Johansson, and Madonna. However, by realizing the changing of the times, LV has cleverly managed to keep up with the development trends of the market.

\section{MARKETING STRATEGY ANALYSIS: HOW DOES LV SUCCESSFULLY TRANSFORM AND OCCUPY THE MARKET}

\subsection{Brand introduction of Louis Vuitton}

Louis Vuitton is a French fashion brand. It was founded by Louis Vuitton in Paris in 1854. At present, Louis Vuitton, from generation to generation, by maintaining excellent quality, outstanding creativity, and exquisite craftsmanship, has become a symbol of fashion travel art. Nowadays, Louis Vuitton is not limited to the design and sale of high-grade leather goods and bags but has become involved in fashion, jewelry, watches, wine, cosmetics, perfume, books, and other fields. It is famous for its two-letter initials LV as the symbol of luxury goods. On June 6, 2017, the 2017 BrandZ Top 100 Most Valuable Global Brands announced that Louis Vuitton was ranked 29th. Its headquarters is located on the Champs Elysees in Paris, France.[10]

\subsection{Analysis of brand marketing strategy of $L V$}

\subsubsection{The background of the $L V$}

The brand image of LV is the art of travel. The main positioning of this brand is luxury, but comfortable and convenient travel life, which can be clearly seen from its official advertisements and brand image. A successful enterprise must have a good brand image and good products for great development, which can improve the grade of products and protect its intellectual property rights. Further, a good brand is the spokesman of the integrity of the product, but all of this is based on the excellence of the product. Products must have a good brand to carry, and a good brand requires an excellent marketing team to direct it and make creative plans to strengthen brand development.

Before the company's transformation, most of product lines were cases and bags, which evoked a feeling of tradition, classic, luxury, and excellent quality. Ten to twenty years ago, the Internet was far from as developed as it is now, and LV chose to utilize offline marketing and advertising on TV to promote its brand of bags and other products, such as in China. LV utilized the richest Hong Kong television station in Southern China for 90 seconds of advertisements to display their brand to consumers. 
Today, however, the Internet is highly developed, and LV has chosen to create more product lines to meet young consuming habits. They have placed advertisements on various online platforms to attract young consumption. Moreover, they have chosen Kris $\mathrm{Wu}$, a new celebrity of the younger generation, as their spokesmen in China, thus making their brand "younger.

\subsubsection{A fusion of classics and trends}

Over the 150 years of development of LV, travel cases and bags have been the anchor. Exquisite craftsmanship and classic and durable pragmatism is its brand purpose. LV suitcases and bags are not afraid of wind and rain and the stresses of travel. Meanwhile, luxury and artistic feelings are reflected in the details, which is its unique brand charm. LV has its amazing product image, pattern, and classic brown leather in consumers' fixed impression. When LV began its transformation at the beginning of 2000, it was vital to discuss how to make the characteristics of LV and its co-brand stand side by side in one product without seeming inconsistent. In the numerous co-branded designs, we can easily find a rule: LV is good at integrating the design styles of its brand and co-branded brands, such as the co-branded series of LV and Supreme. LV is a household luxury brand in the US, while Supreme is an emerging street brand. The two styles have nothing to do with each other. However, Louis inclusion of signature rectangular box logo in its monogram pattern is a sign of a strong alliance between the two fashion avant-garde houses and the harmonious coexistence of elegant aristocracy and street flair.

\subsubsection{New faces of the brand contribute to the development}

Every time LV announces its global brand ambassadors, it helps LV achieve a higher level of brand image positioning. LV has many different levels of spokespersons the first level of global brand ambassadors is higher than global brand ambassadors, who are higher than global brand friends; the second level of full-line endorsements is higher than branch endorsements, which is higher than series endorsements, which is higher than product endorsements. From this, we can see that even though LV seems to have many spokespersons the spokespersons are actually hierarchical. The most important, of course, is the LV global brand spokesperson. Global brand ambassadors are few, but their role is not small. For instance: China, the most populous country globally, has only one female star, Fan Bingbing, as the spokesperson of LV series. Further, there are only two other LV spokespersons of Asian descent: Wu Yifan and Liu Yifei. Through the understanding of past spokespersons, we have found that global brand spokespersons not only have super popularity through which they can bring huge traffic; at the same time, they have certain international market recognition and excellent pieces. Take Liu Yifei as an example. Before signing with the LV brand, she played the role of Mulan. Mulan is a traditional heroine in Chinese culture. She made the feat of going out and fighting for her father in the feudal era in ancient times and inspiring the people to break the old customs of traditional society. After the movie was broadcast, Liu's national image in the minds of the Chinese people became more solidified. At the same time, this brought herself a better reputation and resources.

To conclude, signing Liu Yifei was a practical step to open the Chinese market for the LV brand quickly. At the same time, good domestic reputation can help the LV brand develop steadily in China. Therefore, as LV wants to develop rapidly in China, Liu Yifei has been a good choice.

\section{CAUSE ANALYSIS AND TREND ANALYSIS OF LV BRAND MARKETING STRATEGY CHANGE}

\subsection{LV brand strategy transformation trends}

\subsubsection{Brand marketing strategy transformation trends}

In the mid-19th century, a Frenchman named Louis Vuitton opened his first shop in downtown Paris, specializing in leather goods and travel bags. Because of their excellent design and outstanding quality, these bags become necessary for aristocrats to go out or travel with. For this reason, LV has established the development concept of focusing on aristocratic users and high-end markets [11]. LV, however, has developed more product categories over hundreds of years and expanded its territory in different fields. In recent years, Louis Vuitton has grown into the mass market, through which the brand has stepped down from its pedestal to embrace the mass market.

In 2014, LVMH Group, the parent company, spent $\$ 100$ million to acquire more than $90 \%$ of the stake in CrystalJade, a Chinese restaurant, through its private equity fund L Capital Asia, to enter mainland Chinese food market. Now, most consumers who cannot afford to buy bags that sell for tens of thousands of RMB can instead enjoy an authentic LV Xiaolongbao, or "shrimp dumpling".

For such luxury sub-branded restaurants, their value is to make the luxury brand more exposed to consumers, gather popularity, sell the product lifestyle, and more importantly, represent an alternative offline experience, allowing the brand to bring about changes in the business model. In other words, such stores also appeal to the target audience who may buy luxury goods in the future. In this way, its customers are undoubtedly few. 
Its current operation relies on the reputation of luxury brands, and its future development will be limited.

\subsubsection{The art of travel Brand Image}

Customer base as a classic luxury brand has evolved from the royal palace to the aristocracy and then to the public. Its brand positioning has always been progressing to a universal basis. This year, LV signed a new global brand spokesperson, Liu Yifei, demonstrating its positioning for future planning. Liu Yifei is not a new streaming star; she has been in the show business for a long time and has a solid fan base. According to the age of Liu Yifei and the age of her fans, it is implied that positioning for the age group of their customers is over 30 , which is more representative of the population.

Although LV is becoming more and more popular, it still positions itself as the top luxury brand. The price of $\mathrm{LV}$ is far higher than the average consumption spending of the majority. For their shops, LV also uses advanced and luxurious decoration styles. However, official style positioning is low-key and luxury, which also corresponds to the needs of its age group.

\subsubsection{Traffic helps the market attract attention}

As a luxury brand with a storied history, LV has always maintained a mysterious and high-end line. LV itself should be more famous than any other star and does not need the so-called star bonus. However, on October 31, 2018, Louis Vuitton made an unprecedented announcement: singer, music producer and actor Kris $\mathrm{Wu}$ would officially become its brand spokesperson. In fact, this is the first time in history that it announced a brand spokesperson. As the millennials increasingly occupy the market, Louis Vuitton realized that in order to reach the young market, it must abandon its old status as a luxury of the aristocracy and choose new marketing ideas, such as collaboration with Kris Wu.

For a brand to have credibility, it must have a suitable spokesman. In 2016, when Kris $\mathrm{Wu}$ was the brand spokesperson of Burberry, the sales of the brand in the third quarter of that year rose to $25 \%$ [12], which proved that Kris's traffic could help the brand gain attention, lead the company's vision, and make more people pay attention to the brand's products. China is undoubtedly the largest market in the world, and Kris popularity in China is enough to easily open up the Chinese fashion market for Louis Vuitton. Recent data shows that LV has ranked first in the Top 10 of luxury brands in China, and an important factor contributing to this achievement is that $\mathrm{LV}$ has chosen $\mathrm{Wu}$ Kris as its brand spokesperson. It has been a very important decision for $\mathrm{LV}$ to choose $\mathrm{Kris} \mathrm{Wu}$ as its spokesperson, as this has allowed LV to promote the rapid digital transformation of the brand through young people. The use of traffic stars on behalf of luxury brands to show respect to young people can bring traffic, while young artists can help the brand to achieve youth, narrow the distance between the brand and the new generation of consumers, and move forward with the times. In such a way, looking for traffic as a spokesperson for luxury brands can be a shortcut to transformation.

\subsection{Cause analysis of LV marketing strategy}

\subsubsection{The rapid development of the Internet has changed $L V$}

Since Louis Vuitton entered China in 1992, the brand has thrived. LV only establishes its stores for direct sales, and it has always insisted on using exclusive stores as the only sales channel. However, with the rapid development of the Internet, online publicity has become a direction that cannot be ignored, no matter the industry. Since luxury consumer groups have involved a large number of young people and they are also the main users of various Internet platforms, luxury brands have gradually shifted their marketing to young people because the old, the former main consumer groups, are no longer enough to support the development needs of luxury brands. Therefore, if they want to continue to expand their market share and compete with their competitors, luxury brands can only gradually give up their highly targeted publicity for the middle-aged and elderly and focus on attracting the young. [13] Although young people may not have as much consumption power as middle-aged and older people, their superiority in numbers and innovative thinking can bring more vitality to luxury brands. Luxury brands need to use various Internet platforms for marketing their brands, such as by signing contracts with popular stars and advertising in various mobile apps. All these are excellent ways to attract young people to understand and consume luxury goods. [145]

\subsubsection{Internal requirements for brand development}

LV, Dior, and other world-famous luxury companies with a history of at least one hundred years are highly adaptable to the times. They can survive in changing times because they can adapt to different trends by innovating and adjusting their marketing strategies and product design ideas accordingly. If they fail to do so, they will be swept away by the tide of the times, along with other obscure and bankrupt companies. For example, with the rapid development of the Internet, significant competitors have begun to transform their marketing strategies and design ideas like Dior or Prada. If $\mathrm{LV}$ chooses to stick to the old rules, it will indeed be eliminated by the times and lose its dominant right in the field of luxury goods. Younger product design is what every luxury brand should pay attention to. 


\subsubsection{Necessity of advocating brand value}

The current era is one of the gradual rise of rights. Women across the world have begun to pursue equal rights and equal responsibilities with men, and at the same time, many feminist institutions have sprung up. Regardless of whether their ultimate goal is to pursue true equality between men and women, this is a major trend. Since the main consumer group of LV is female, most of its production lines are bags, cosmetics, clothes, and other products suitable for women. LV must cater to this trend. Otherwise, LV will not get the recognition and recognition of women. The design of more neutral products can better conform to the design direction of feminism.

\section{CONCLUSION}

By analyzing Louis marketing behaviors and strategies in recent years, we conclude that LV is actively developing towards the millennial generation customer group and Internet e-commerce. We have broken down the structure of the study into three aspects. They are product design, brand positioning, and spokesperson selection. (1) In terms of product design, LV actively cooperates with contemporary fashion brands, seeking to create outstanding new products popular in the modern era. (2) LV is no longer obsessed with maintaining its brand positioning of high-end travel cases and bags but instead develops more product lines to achieve a more down-to-earth marketing effect. (3) I n selecting spokespersons, LV prefers star artists who can highly attract popularity and bring their traffic to promote their brand.

With the development of Internet technology, concept of shopping has changed. Traditional marketing models are no longer enough to capture purchasing power. According to our research, many brands have begun to transition to the younger generation, and LV, as a luxury brand with a history of over a century, is no exception. According to the data we reviewed, millennials generally have a strong buying power, and are receptive to and willing to pay for pioneering fashion ideas. LV has over a hundred years of operational experience and a stable customer group, so this new market cannot be ignored. The accompanying marketing moves, such as co-branding with trendy brands, changing designers, and hiring spokespeople, protect the brand. Market performance in recent years has also shown that LV has seized this opportunity and successfully occupied the position of the top luxury brand in young minds and achieved excellent marketing results.

In general, marketing strategy is to keep up with the development of the times and not to be eliminated by society. According to the content mentioned above, it recognizes that LV has always positioned itself as a top luxury brand. The brand has gone through such a long history and has not been abandoned, which proves the marketing ability of the LV brand. Through replacement of spokespersons, one can clearly understand the company's marketing toward its brand image. LV's image can quickly capture the development of the times, and the brand clearly understands how to grasp the eyes of target customer groups. This is the foundation and advantage that $\mathrm{LV}$ can use to maintain itself in the ranks of top luxury goods.

From the perspective of practical significance, in the marketing strategy and brand transformation, luxury brands represented by LV should pay attention to the communication and binding with young consumers, and pay more attention to the advocacy of LV own consumption concept and value concept so as to expand the group of consumers. LV should not continue to bind our marketing strategy to middle-aged women and should instead focus on expanding the young consumer group. Many young people nowadays pay special attention to the promotion of their personal image, and taking advantage of expensive luxury goods is one of their methods. Therefore, luxury brands can design more products in line with the aesthetic taste of young people to attract their consumption.

With the rapid development of the Internet, aside from luxury brands, companies in general must take advantage of this young platform to occupy more market shares; the huge number of page views brought by the Internet cannot be ignored by the marketing department of any brand, especially of those is the luxury industry. Despite being biased to traditional forms of promotion; it is necessary for these brands to use the Internet to reinvent themselves.

\section{REFERENCES}

[1] Information from: Jan.18,2018. "Luxury goods have recovered from the downturn. What will determine how fast or slow they grow in 2018?". http://fashion.sina.com.cn/s/in/2018-01-18/1057/do c-ifyqtycw9336979.shtml

[2] Information from: Mendaofashion. Sept.23,2019; "LV and League of Legends, why did luxury get involved in esports?". https://www.sohu.com/a/342895232_808349

[3] Tan Shuang. "Who says diamonds are only for love? Luxury jewelry is transforming". Media Group Limited (SEEC). 2017

[4] Huang Xinya. "Research on the transformation strategy of traditional luxury brands in fashion industry based on IMC theory -- taking Gucci as an example". Nanjing University of the Arts. 2020 
[5] Yi Xin. "Discussion on the transformation strategies of traditional luxury brands under the Millennial Generation -- taking Gucci as an example". Communication University of Shanxi. 2019

[6] Information from: Boston Consulting Group. Dec 12, 2020. "The trend of younger consumption of luxury goods". https://www.bcg.com/zh-cn/

[7] Bruno Lannes, Jing Zhang. 20212020 luxury market:

overwhelminghttps://www.bain.cn/pdfs/202012160 240411747.pdf

[8] Information from: XianMeng Entertainment. Jul 05,2019. "Kris Wu has made Louis Vuitton the number one luxury brand in China". https://www.sohu.com/a/325048939_120008196

[9] Information from: Mar 2016 "Behind change of spokesperson: Millennials become the future of the luxury market" https://wap.cnki.net/touch/web/Journal/Article/QQ DY201603023.html

[10] Information from : Cong Lv. Mar 26, 2020. "Luxury giant LV is exploring the mass market. Where is its brand transformation going?".https://baijiahao.baidu.com/s?id=1662223 $850145559728 \& w f r=$ spider $\&$ for $=p c$

[11] Information from : Nov 14, 2013. "LV background data compilation" https://wenku.baidu.com/view/c880d19965ce0508 77321322.html.

[12] Information from: Nov 1,2018. "LV Official Announcement: Kris $\mathrm{Wu}$ as Brand Spokesman! Who is he?". https://www.sohu.com/a/272587194_526419

[13] Website Admin. 25 June 2019. “2019 China Luxury Consumer Behavior Report: Younger, Regionalized and Socialized Trends." Sohu.com. www.sohu.com/a/322781411_120050952.

[14] Website Admin. 12 Mar. 2018. "Behind Classic Heritage Lies a Story like This." Sohu.com, www.sohu.com/a/225354072_99970523. 